\title{
A PROSPECTIVE OBSERVATIONAL STUDY ON SAFETY AND EFFICACY OF HYDROXYCHLOROQUINE AGAINST DICLOFENAC IN OSTEOARTHRITIS
}

\author{
PRAVEEN D ${ }^{1}$, RANADHEER CHOWDARY P $^{1}$, RUJASWINI T ${ }^{2}$, NIVENTHI A $^{2}$, ELANCHEZIYAN $\mathrm{K}^{3}$, VIJEY AANANDHI M ${ }^{3 *}$ \\ ${ }^{1}$ Research Scholar, School of Pharmaceutical Sciences, Vels Institute of Science Technology and Advanced Studies, Chennai, Tamil Nadu, \\ India. ${ }^{2}$ Department of Pharmacy Practice, School of Pharmaceutical Sciences, Vels Institute of Science Technology and Advanced Studies, \\ Chennai, Tamil Nadu, India. ${ }^{3}$ Department of Pharmaceutical Chemistry and Analysis, School of Pharmaceutical Sciences, Vels Institute of \\ Science Technology and Advanced Studies, Chennai, Tamil Nadu, India. Email: hodpchemistry@velsuniv.ac.in
}

Received: 10 October 2018, Revised and Accepted: 11 December 2018

\section{ABSTRACT}

Objective: The main aim of this study is to compare the effectiveness of treatment of osteoarthritis (OA) with hydroxychloroquine against diclofenac and to compare the safety of the treatment of $\mathrm{OA}$ with hydroxychloroquine against diclofenac. The secondary objectives are the comparison of onset and duration of action of both the treatments.

Methods: A prospective interventional study has been done in a tertiary care teaching hospital for 1 year from January 2016 to December 2016 . The interventional model included an active control (diclofenac - nonsteroidal anti-inflammatory drugs). The control group received diclofenac $75 \mathrm{mg}$ for 12 weeks, whereas the test group received hydroxychloroquine $200 \mathrm{mg}$ for 3 months.

Results: Pain control is significantly rapid in diclofenac group, whereas the duration of action is significantly increased in hydroxychloroquine. It can be clearly seen that the hydroxychloroquine group significantly increases the quality of life when compared to diclofenac group. It is clearly seen that the incidence of gastric ulcers is more common in diclofenac group when compared to hydroxychloroquine group.

Conclusion: Hydroxychloroquine offers a newer spectrum in the management of OA. Although it is slow acting, it has significantly increased the quality of patient as it can have a prolonged action. Hence, hydroxychloroquine can be used as a newer entity in the management of OA.

Keywords: Osteoarthritis, Hydroxychloroquine, Diclofenac.

(c) 2018 The Authors. Published by Innovare Academic Sciences Pvt Ltd. This is an open access article under the CC BY license (http://creativecommons. org/licenses/by/4. 0/) DOI: http://dx.doi.org/10.22159/ajpcr.2018.v11s4.31688

\section{INTRODUCTION}

Osteoarthritis $(\mathrm{OA})$ is the most widespread type among arthritis, triggering a considerable joint aches and fragility. $\mathrm{OA}$ is one of the chief reasons of health-care outflow, and its occurrence will further upsurge with the old-age people. Existing treatments for OA have significant restrictions and novel analgesic therapies are required. Synovitis is predominant in $\mathrm{OA}$ and is usually accompanied with pain. For treating synovitis in inflammatory arthritis, the hydroxychloroquines are used [1].

Hydroxychloroquine is an aminoquinolone primarily an antimalarial drug. It inhibits movement of neutrophils and chemotaxis of eosinophils and damages complement-associated antigen-antibody reactions $[2,3]$.

Nonsteroidal anti-inflammatory drugs (NSAIDs) are enzyme inhibitors. They block cyclooxygenase (COX-1 and COX-2 enzymes), which is liable for the production of prostaglandins and thromboxane $[4,5]$.

\section{Aim}

The main aim is to compare the effectiveness of treatment of OA with hydroxychloroquine against diclofenac and to compare the safety of treatment of $\mathrm{OA}$ with hydroxychloroquine against diclofenac. The secondary objectives are the comparison of onset and duration of action of both the treatments.

\section{METHODS}

\section{Sample size}

Sample size was estimated with a prevalence of 100 patients. The estimated sample size with a confidence interval of $95 \%$ was found to be 80 with a $2.75 \%$ margin of error.

\section{Study design}

A prospective interventional study has been carried out in a tertiary care hospital for 1 year from January 2017 to December 2017. The interventional model included an active control (diclofenac - NSAIDs).

\section{Patient selection}

Inclusion criteria

The following criteria were included in the study:

- Patients of both sexes above the age of 18 years.

- Patients diagnosed with OA.

- Patients who fulfill the criteria for OA as per the American College of Rheumatology.

\section{Exclusion criteria}

The following criteria were excluded from the study:

- Pregnant and nursing women.

- People diagnosed with multiple inflammation.

- People diagnosed with rheumatoid arthritis or have positive rheumatoid antigen.

- Patients who are known case of malaria at the time of inclusion.

- Patients with serum uric acid levels above $6.8 \mathrm{mg} /$ day.

An informed consent has been obtained from all the included patients. Patients' confidentiality has been maintained throughout this study. The work has been approved by the Institutional Ethics Committee IEC/VELS/DOPV/2016/33.

A specially designed pro forma has been utilized to carry out this study. Patients demographics such as age, sex, laboratory values, patient medical history etc were collected. The patient was followed up for every month. 
The control group received diclofenac $75 \mathrm{mg}$ for 12 weeks, whereas the test group received hydroxychloroquine $200 \mathrm{mg}$ BD for 3 months. Patients' quality of life is measured before the initiation of the study as well as the conclusion of 3 months. Standard validated SF-12 questionnaire is administered before and after the end of intervention. Physical and mental component scoring was assessed. Laboratory data such as erythrocyte sedimentation rate were estimated to compare the efficacy.

\section{Statistical analysis}

One sample student $t$-test was used to compare the quality of life among the patients. Chi-squared test was used to compare the control of $95 \%$ and a $p<0.05$ is considered to be statistically significant.

\section{RESULTS}

The following results were obtained in the study.

Table 1 shows that female are more prone to $\mathrm{OA}$ when compared to male distribution.

Table 2 shows that patients between 50 and 65 years of age are more prone to $\mathrm{OA}$ when compared to other age distribution.

Table 1: Gender distribution

\begin{tabular}{ll}
\hline Gender & Number of patients (\%) \\
\hline Male & $16(25)$ \\
Female & $64(75)$ \\
\hline
\end{tabular}

Table 2: Age distribution

\begin{tabular}{ll}
\hline Age group $(\mathbf{n = 8 0})$ & Number of patients $\mathbf{( \% )}$ \\
\hline 18-35 years & $8(10)$ \\
$35-50$ years & $20(25)$ \\
$50-65$ years & $36(45)$ \\
$>65$ years & $16(20)$ \\
\hline
\end{tabular}

Table 3: OA type

\begin{tabular}{ll}
\hline OA type & Number of patients (\%) \\
\hline Knee & $72(90.00)$ \\
Hip & $6(7.50)$ \\
Hand & $2(2.50)$ \\
\hline OA: Osteoarthritis &
\end{tabular}

Table 4: Comorbidities

\begin{tabular}{ll}
\hline Comorbidity & Number of patients (\%) \\
\hline DM & $24(30.00)$ \\
HTN & $20(25.00)$ \\
BA & $7(8.75)$ \\
Dyslipidemia & $3(3.75)$ \\
No comorbidities & $12(15.00)$ \\
\hline
\end{tabular}

Table 3 shows that knee OA patients are more prone when compared to other types.

Table 4 shows that diabetes mellitus (DM) patients are more prone to OA when compared to other comorbidities (Tables 5-8).

Pain control is significantly rapid in diclofenac group, whereas the duration of action is significantly increased in hydroxychloroquine.

It can be clearly seen that the hydroxychloroquine group significantly increases the quality of life when compared to diclofenac group.

It is clearly seen that the incidence of gastric ulcers is more common in diclofenac group when compared to hydroxychloroquine group.

\section{DISCUSSION}

In general, women are more prone to the $\mathrm{OA}$ when compared to the men. Specialist's assessment is that almost $60 \%$ of the women in the US are having OA. Similar patterns were reported in our study.

The anatomy of a female's physique is organized in such a way which may show a part in her risk for OA of the knees. Specifically, woman tends to have broader hips, in which some specialists' belief affects the position of the knee and causes irregular stress on the knees, leading to $\mathrm{OA}[6]$.

As age increases, the highest risk factor for $\mathrm{OA}$ is also increases, and it is not an unavoidable magnitude of getting aged. The elderly changes in joint tissues that fund to the growth of OA include cell senescence that fallouts in the expansion of the senescent secretory phenotype and aging variations in the matrix, including the development of progressive glycation end products that affect the mechanical possessions of joint tissues $[7,8]$

Knee $\mathrm{OA}$ is of additional importance not only for its significant occurrence rate related with other forms of $\mathrm{OA}$ but also for its appearance at earlier age groups predominantly in younger age groups of overweight women. The incidence of knee OA increases by age and further increases with lengthier lifetime and advanced usual weight of the population [9].

DM and hyperglycemia are correlated with OA in some epidemiological studies. Moreover, the relationship within the two diseases might be supported by the lethal role of glucose spare through the buildup of advanced glycation end products, oxidative stress, and promotion of systemic inflammation $[10,11]$.

Hydroxychloroquine blocks the action of certain chemical messengers that are responsible for inflammation, swelling, and redness associated with certain joint diseases. Although it is slow acting, duration of the action of hydroxychloroquine is more when compared to diclofenac (NSAIDs).

Diclofenac spreads into and out of the synovial fluid. Dispersal into the joints happens when plasma levels are upper than those in the synovial fluid, after which the progression reverses and synovial fluid levels are

Table 5: Test characteristics

\begin{tabular}{llll}
\hline Characteristics & Group A (n=40) diclofenac (\%) & Group B (n=40) hydroxychloroquine (\%) & p values \\
\hline Age $($ mean \pm SEM) & $51.66 \pm 2.17$ & $50.27 \pm 1.36$ & 0.1726 \\
Female $(\mathrm{n}=64)$ & 35 & 29 & 0.3428 \\
Alcoholic & $3(3.75)$ & $4(5.00)$ & 0.2217 \\
Smoker & $1(1.25)$ & $0(0.00)$ & 0.2916 \\
ESR (mean \pm SEM) (before treatment) & $37.6 \pm 4.12$ & $35.8 \pm 2.76$ & 0.2317 \\
Pain control time & $1.24 \pm 0.6 \mathrm{~h}$ & $3.12 \pm 2.24 \mathrm{~h}$ & $0.0496^{*}$ \\
Time taken for remission of pain & $2.56 \pm 0.3 \mathrm{~h}$ & $7.44 \pm 1.16 \mathrm{~h}$ & $0.0047^{*}$ \\
\hline
\end{tabular}


Table 6: PCS and MCS

\begin{tabular}{lllllll}
\hline Groups & Group A & & & Group B & \\
\cline { 2 - 5 } & Before & After (a) & p value & Before & After (a) & p value \\
\hline PCS & $36.12+2.17$ & $44.72+1.26$ & 0.0927 & $36.82+1.17$ & $54.17+2.26$ & $0.0236^{*}$ \\
MCS & $31.16+2.47$ & $39.16+0.97$ & 0.0628 & $31.29+1.62$ & $51.17+1.12$ & $0.0059^{*}$ \\
\hline
\end{tabular}

${ }^{a}$ Comparison of after treatment of Group A and Group B, *p<0.05 is considered significant, PCS: Physical component score, MCS: Mental component score

Table 7: Treatment efficacy after 3 months depending on SF-12

\begin{tabular}{lll}
\hline Groups & Number of patients with improvement & Number of patients without improvement \\
\hline Group A & 28 & 12 \\
Group B & $35^{*}$ & 5 \\
Total & 6.3 & 17 \\
\hline
\end{tabular}

On performing $\chi^{2}$, Group B value was found to be 12.167 and p value was found to be 0.0396 . p $<0.05$ is considered to be statistically significant at $95 \%$ confidence interval

Table 8: ADR reported in the study

\begin{tabular}{llll}
\hline ADR & Group A (n=40) & Group B (n=40) & p value \\
\hline GI ulcers & $12(15.00)$ & $2(2.50)$ & 0.0327 \\
Nausea/vomiting & $7(8.75)$ & $4(5.00)$ & 0.0926 \\
Tinnitus & 0 & $4(5.00)$ & 0.0927 \\
Leucopenia & $3(3.75)$ & $9(11.25)$ & 0.2716 \\
\hline
\end{tabular}

ADR: Adverse drug reactions, GI: Gastric. $p<0.05$ is considered to be statistically significant at $95 \%$ confidence interval

higher than plasma levels. It is not known whether diffusion into the joint plays a role in the efficiency of diclofenac. However, it shows rapid onset of action when compared to hydroxychloroquine.

Gastric acid plays a tolerant role both in Helicobacter pylori and NSAIDinduced ulcers. Thus proton-pump inhibitors are useful for primary and secondary ulcer prevention [12].

\section{CONCLUSION}

Hydroxychloroquine offers a newer spectrum in the management of OA. Although it is slow acting, it has significantly increased the quality of patient as it can have a prolonged action. Hence, hydroxychloroquine can be used as a newer entity in the management of OA.

\section{ACKNOWLEDGMENT}

The authors are thankful to the Vels Institute of Science Technology and Advanced Studies and its management for providing constant support and research facilities.

\section{REFERENCES}

1. Crofford LJ, Lipsky PE, Brooks P, Abramson SB, Simon LS, van de Putte LB, et al. Basic biology and clinical application of specific cyclooxygenase-2 inhibitors. Arthritis Rheum 2000;43:4-13.

2. Lanas A. Nonsteroidal antiinflammatory drugs and cyclooxygenase inhibition in the gastrointestinal tract: A trip from peptic ulcer to colon cancer. Am J Med Sci 2009;338:96-106.

3. Massó González EL, Patrignani P, Tacconelli S, García Rodríguez LA. Variability among nonsteroidal antiinflammatory drugs in risk of upper gastrointestinal bleeding. Arthritis Rheum 2010;62:1592-601.

4. Simmons DL, Botting RM, Hla T. Cyclooxygenase isozymes: The biology of prostaglandin synthesis and inhibition. Pharmacol Rev 2004;56:387-437.

5. FitzGerald GA, Patrono C. The coxibs, selective inhibitors of cyclooxygenase-2. N Engl J Med 2001;345:433-42.

6. Hochberg MC. New directions in symptomatic therapy for patients with osteoarthritis and rheumatoid arthritis. Semin Arthritis Rheum 2002;32:4-14

7. Brater DC, Harris C, Redfern JS, Gertz BJ. Renal effects of COX-2selective inhibitors. Am J Nephrol 2001;21:1-5.

8. Robertson CR, Rice JR, Allen NB: Treatment of erosive osteoarthritis with hydroxchloroquine. Arthritis Rheum 1993;36(Suppl):S167.

9. Bryant LR, des Rosier KF, Carpenter MT. Hydroxychloroquine in the treatment of erosive osteoarthritis. J Rheumatol 1995;22:1527-31.

10. Punzi L, Bertazzolo N, Pianon M, Michelotto M, Todesco S. Soluble interleukin 2 receptors and treatment with hydroxychloroquine in erosive osteoarthritis. J Rheumatol 1996;23:1477-8.

11. Karres I, Kremer JP, Dietl I, Steckholzer U, Jochum M, Ertel W, et al. Chloroquine inhibits proinflammatory cytokine release into human whole blood. Am J Physiol 1998;274:R1058-64.

12. Weber SM, Levitz SM. Chloroquine interferes with lipopolysaccharideinduced TNF-alpha gene expression by a nonlysosomotropic mechanism. J Immunol 2000;165:1534-40. 